\title{
REVISIONES
}

\section{Modelos de gestión de la diversidad cultural para la escolarización de alumnado inmigrante en las escuelas chilenas: Desafíos para la interculturalidad actual}

\author{
Management Models of Cultural Diversity for the Schooling of \\ Immigrant Students in Chilean Schools: Challenges for the current intercultural \\ Modelos de gestão da diversidade cultural para a escolarização \\ de alunos imigrantes nas escolas chilenas: Desafios para o atual intercultural
}

\section{Felipe Jiménez Vargas. ${ }^{a}$}

a Escuela de Psicología, Pontificia Universidad Católica de Valparaíso.

Fono: 56-32-2274363. Correo electrónico: felipe.jimenez@ucv.cl

\section{RESUMEN}

El presente trabajo ofrece una reflexión en torno a los desafíos que en la actualidad siguen presentes en materia de educación intercultural en Chile, centrando su mirada en la tensión que supone para ésta la llegada cada vez más sistemática de alumnado inmigrante a las aulas. Desde una revisión centrada en los diversos modelos de gestión de la diversidad cultural se ofrece una tipología que permita a las escuelas con alumnado inmigrante, a través de su equipo directivo y sus profesores, avanzar en la comprensión de dichos modelos de gestión e instalar la temática como una preocupación de primer orden.

Palabras clave: diversidad cultural, educación intercultural, inmigración.

\section{ABSTRACT}

This paper offers a reflection on the challenges that are still present today in intercultural education in Chile, focusing his gaze on the tension that this poses to the increasingly systematic arrival of immigrant students into the classroom. From a review focused on the various models for managing cultural diversity it is provided a typology that allows schools with immigrant students, through their team and their teachers, to advance the understanding of these management models and installing the issue as a major concern.

Key words: cultural diversity, intercultural education, immigration.

\section{RESUMO}

Oferece-se uma reflexão sobre os desafios que ainda estão presentes na educação intercultural no Chile, focando a tensão que isto representa para a chegada em salas de aula, cada vez mais sistemática, de estudantes imigrantes. A partir de uma análise focada em diversos modelos para a gestão da diversidade cultural, oferece-se uma tipologia que permite que as escolas com alunos imigrantes, por meio da equipe e seus professores, faça avançar a compreensão destes modelos de gestão e instalar a questão como uma grande preocupação.

Palavras chave: diversidade cultural, educação intercultural, imigração. 


\section{INTRODUCCION}

De acuerdo a los datos preliminares del censo 2012 (Instituto Nacional de Estadísticas [INE], 2012), el porcentaje de población inmigrante en Chile se ubica alrededor del 2,2\%, correspondiendo a un poco más de 400.000 personas. Si bien puede resultar una cifra relativamente baja en comparación con la realidad demográfica de otros países y continentes, no deja de ser relevante que al comparar los datos con el censo realizado el año 2002, el porcentaje de inmigrantes haya aumentado en cerca de un 50\%. Del mismo modo, podemos observar que de acuerdo al censo 2002 más de 35.000 personas se encuentran dentro de la edad de escolarización obligatoria y es de esperar, por tanto, que un alto porcentaje de dicho número se encuentre matriculado en alguna institución educativa del país.

Si bien Chile cuenta desde el año 1996 con un Programa de Educación Intercultural Bilingüe (MINEDUC, 2002), que ha dado lugar a la creación por parte de la Junta Nacional de Auxilio Escolar y Becas (JUNAEB) de los primeros jardines infantiles interculturales, esta política educativa sigue en la actualidad centrada con demasiado énfasis en una interculturalidad basada en el reconocimiento y la reivindicación de pueblos originarios (Montecinos, 2004) -fundamentalmente en las lenguas y costumbres-, no contemplando por tanto la diversidad étnica y cultural aportada por los colectivos inmigrantes que llegan hasta nuestro país.

Sumado a lo anterior, y en la medida que la multiculturalización de nuestras aulas es un fenómeno relativamente reciente y sin una visibilidad suficiente, carecemos en nuestro contexto de investigaciones que puedan dar cuenta de las características, fortalezas y debilidades de los procesos de escolarización del alumnado inmigrante y su relación con el alumnado de la cultura mayoritaria. Producto del mismo desconocimiento en esta materia es que no tenemos suficiente información respecto al éxito o fracaso de este grupo de estudiantes en las aulas chilenas y, por ende, para poder compararlo con los resultados de los estudiantes chilenos. Sin embargo, podemos tomar como referencia la experiencia de países como España que cuenta con una mayor tradición en la escolarización de alumnado inmigrante, que en comunidades autónomas como Cataluña para el curso escolar 2009/2010 el número de alumnos y alumnas de origen extranjero alcanzó una cifra de 160.468, correspondiente al $21 \%{ }^{1}$ de la matriculación total.

En la medida que la escolarización del alumnado inmigrante fuese exitosa no existirían suficientes razones para preocuparse y para hacer de ésta una problemática de investigación. No obstante, los datos disponibles muestran justamente lo contrario.

Si hay una problemática que ha permitido aglutinar los desarrollos e investigaciones y ha podido dar cuenta de la forma en que la escolarización del alumnado inmigrante se ha llevado a cabo en las escuelas, es la tensión entre el éxito y el fracaso escolar. Si tomamos como punto de partida los resultados disponibles de la prueba PISA realizada el año $2009^{2}$, podemos ver con claridad que el rendimiento obtenido por el alumnado originario o autóctono es sensiblemente superior al obtenido por el alumnado de origen inmigrante. Para el caso de Cataluña son 82 puntos promedio los que separa al alumnado tomando como referencia su lugar de origen. Hannoun (1992), McCarthy (1994) y Perrenoud (1998) desde el campo internacional, así como Besalú y Vila (2007), Jordán (1996) y Lalueza,

Cifras de la inmigración en España, Ministerio de Educación, Cultura y Deporte.

Informe español, disponible en: www.educacion.gob.es 
Crespo y Luque $(2010,2009)$ en el plano local, han contribuido a la comprensión de este fenómeno y han permitido descifrar las claves para su comprensión.

Más allá de indicadores numéricos como el rendimiento académico, que muchas veces impide -más que ayuda- calibrar la magnitud cualitativa de una problemática como ésta, estos autores nos muestran que es el alumnado perteneciente a minorías étnicas y/o inmigrante el que con mayor fuerza se ha visto envuelto en situaciones de mayor absentismo escolar, mayor abandono del sistema educativo y, por consiguiente, de mayor probabilidad de exclusión y segregación social.

Dentro del campo del fracaso escolar, los desarrollos de Banks (1989), Ogbu (2005), Lalueza, Crespo y Luque (2010) y Echeita (2002) han contribuido a complejizar las explicaciones tradicionales en torno al déficit cultural de los grupos minoritarios y/o inmigrantes, resaltando la importancia y los riesgos que las discontinuidades entre la cultura escolar y la cultura familiar tienen al momento de comprender las razones por la cuales parte del alumnado fracasa en la escuela. De forma unánime, aunque con matices, estos autores nos advierten de la dificultad o incluso la imposibilidad de lograr el éxito escolar del alumnado minoritario si la escuela como institución se muestra insensible a los cambios sociales, y continúa operando -desde el punto de vista de su estructura, funcionamiento y oferta curricular- bajo una lógica monocultural, no promoviendo, por tanto, el despliegue de continuidades entre la cultura escolar y las culturas minoritarias.

Conciliando las explicaciones y argumentaciones aportadas en torno al éxito y el fracaso escolar del alumnado inmigrante, podemos ver que lejos de variables de naturaleza individual e incluso de origen cultural, el éxito y fracaso escolar del alumnado inmigrante está condicionado fuertemente por los modelos de gestión de la diversidad cultural que implementa la escuela en contextos de multiculturalidad. Esto quiere decir que dependiendo de la forma en que la escuela afronte la llegada y escolarización de alumnado de origen inmigrante, y dependiendo, por ende, de los principios y valores educativos que impregnen sus prácticas pedagógicas, la experiencia educativa del alumnado inmigrante podrá moverse entre el continuo del éxito y del fracaso escolar. Resulta fundamental, por tanto, poder conocer qué modelos existentes en la actualidad pueden ser utilizados por la escuela para gestionar la diversidad cultural del alumnado producto de la incorporación de estudiantes de origen inmigrante.

\section{MODELOS DE GESTIÓN EN LA ESCUELA: ALTERNATIVAS POSIBLES}

Comenzaremos señalando que gestión de la diversidad viene a ser la traducción del término diversity management que surge en el contexto empresarial anglosajón a lo largo de la segunda mitad del siglo XX, el cual denota una preocupación por la necesidad de considerar la diversidad como determinante de lo organizativo, dando lugar, por consiguiente, a prácticas racionalmente organizativas de dicha diversidad (Essomba, 2008). Sin embargo, un concepto que nace en el campo del mundo empresarial pronto comienza a ser considerado útil desde otros ámbitos sociales, fundamentalmente a partir de las necesidades que los cambios demográficos implicaron para la organización social (Essomba, 2008).

Uno de los escenarios sociales donde justamente más ha afectado la composición demográfica de sus participantes ha sido la escuela, y es por tanto allí donde la idea de gestionar la diversidad cultural ha cobrado sentido y urgencia, a raíz del aumento cada vez más progresivo de alumnado perteneciente a familias inmigradas y/o extranjeras. 
Si bien existen diferentes tipologías para caracterizar, sintetizar y organizar los diferentes modelos de gestión de la diversidad cultural en la escuela (COLECTIVO AMANI, 2004; Hannoun, 1992; Jiménez, 2012; UNESCO, 2009), presentaremos una propuesta que no sólo es bastante exhaustiva, sino que además resulta ser muy intuitiva, permitiendo que sus características e implicancias puedan ser comprendidas por cualquier tipo de público lector. Revisemos a continuación nuestra propuesta y sus planteamientos.

\subsection{LA ESCUELA EXCLUSORA}

Como su nombre lo indica, corresponde a aquellos contextos escolares que podríamos llamar pre-integradores, en los cuales la educación fue pensada para un determinado tipo de ciudadanos, razón por la cual aquellos que no reunieran las características contempladas dentro de dicha categoría, quedaban al margen de esta institución social y, por tanto, de sus beneficios. Realizando una mirada retrospectiva podemos ver que ha sido el caso de la clase obrera y las mujeres durante el siglo XIX, en tanto la educación estaba destinada a los hijos de la nobleza y la burguesía como mecanismo de perpetuación y reproducción social (Bourdieu, 2005; Bourdieu y Passeron, 1995). No hace falta en todo caso ir tan atrás en el tiempo para encontrar ejemplos de exclusión en el ámbito escolar, pues como nos revela Besalú (2002), los grupos desaventajados -socialmente hablando- por razones de género, clase o étnia, han seguido la misma trayectoria con relación a su escolarización, siendo el punto de partida la marginación y/o expulsión. Lo que observamos detrás de una lógica exclusora es el rechazo de los grupos dominantes a que los miembros de las culturas foráneas y/o minoritarias tengan acceso y adopten la cultura hegemónica (Berry, 1997), en este caso a partir de la participación en la escuela como institución transmisora de ella.

La experiencia del pueblo gitano en España hasta la creación de escuelas puente ${ }^{3}$, las que funcionaron en el período comprendido entre el año 1978 y 1986 y desaparecieron por la entrada en vigor de la LODE, es un fiel reflejo de la situación de desescolarización en la que se encontraban los hijos e hijas de familias gitanas durante la segunda mitad del siglo XX, y que expresa una voluntad excluyente como manera de organizar la diversidad cultural en la escuela. Por otro lado, y centrando la mirada en nuestro contexto local, la expulsión de alumnas embarazadas, la no matriculación de alumnado de orientación homosexual, e incluso la cancelación de matrícula de estudiantes por la separación de los padres en colegios pertenecientes a congregaciones religiosas, son ejemplos que hace años nos han llegado a través de la prensa local y que evidencian, al igual que el caso de los gitanos en España, una actitud de exclusión hacia determinados estudiantes.

Enlazando los ejemplos que hemos dado para graficar la escuela exclusora, podemos observar que la tensión constitutiva de la escuela se resuelve disolviendo la diversidad posible, de manera tal que se generan barreras para evitar que ésta llegue a su ámbito de acción. Para Torres Santomé (2008), existen al mismo tiempo experiencias más sutiles y actuales de exclusión simbólica, pero que desde nuestro punto de vista se relacionan mayormente con la escuela asimilacionista, razón por la cual reservaremos su atención para cuando nos refiramos a ella como modelo de atención a la diversidad.

Escuelas diseñadas exclusivamente para la escolarización de alumnado perteneciente a etnia gitana y que, como su nombre lo indica, intentaban convertirse en una experiencia de transición hacia la escolarización en contextos educativos ordinarios. 


\subsection{LA ESCUELA SEGREGACIONISTA}

En la medida que la declaración universal de los derechos humanos de 1948 y la declaración universal de los derechos del niño en 1959 van siendo tomados como marcos referenciales para nutrir los principios educativos (Canimas y Carbonell, 2008), el acceso a la educación se fue transformando al interior de las políticas públicas de los países europeos y latinoamericanos en una consiga, dejando de ser un derecho y pasando a convertirse en una obligación, amparada en la necesidad pública del aumento de la cobertura. Es en este contexto que sin mediar razones de sexo, origen, clase social o étnia, todas las personas comprendidas en un rango de edad determinado, pueden y deben acceder a la escolarización formal. Sin embargo, esta voluntad democratizadora no significó inmediatamente que la escuela albergara a la diversidad de la población, como veíamos anteriormente respecto a hombres y mujeres, hijos e hijas de la clase obrera y de las clases acomodadas, así como a los de familias pertenecientes a minorías étnicas o inmigradas, sino que operó bajo una lógica de especialización (Essomba, 2006) que, en una primera fase y desde una perspectiva radical, supuso la creación de escuelas diferenciadas de acuerdo a unas determinadas variables. En otras palabras, detrás de la lógica segregacionista existe la convicción teórica de que a cada cultura o a cada grupo social le corresponde una escuela específica (Hannoun, 1992). En la medida que bajo la lógica segregacionista existe una conceptualización de la y las culturas como entidades inconmensurables y excluyentes, las que suponen a su vez distintos valores y vías de desarrollo (Banks, 1986), es necesario configurar espacios de aprendizaje y conocimiento que tengan en cuenta estos elementos.

En la medida que determinados colectivos presentan características peculiares pero divergentes con relación a la mayoría dominante, lo que se requiere es el diseño de una atención exclusiva y especializada, de manera que a través de una pedagogía adaptada, se cumplan los objetivos escolares (San Román, 1998). Ejemplos de la lógica segregacionista los podemos encontrar en escuelas que, al margen de los actuales planteamientos en torno a la importancia de la coeducación (Subirats, 1994), optan por separar al alumnado de acuerdo al género; países en los que se han creado escuelas de acuerdo al origen étnico-religioso del alumnado (para musulmanes, por ejemplo), y; finalmente, todas aquellas escuelas que bajo el principio de la educación especial (García-Gómez y Aldana-González, 2010) han concentrado al alumnado que, presentando algún tipo de diferencia, no podrían seguir con normalidad las trayectorias educativas de la escuela normal. La educación especial sería entonces un ejemplo de cómo la lógica de la homogeneidad es llevada a su paroxismo con relación a la agrupación del alumnado de acuerdo a determinadas diferencias sustanciales que dificultan su escolarización en contextos ordinarios (Pujolàs, 2012).

Los planteamientos revisados hasta ahora con relación a la escuela exclusora y la escuela segregadora nos aportan elementos valiosos para ir configurando un mapa historiográfico de cómo se ha entendido y atendido la diversidad desde un espacio particular como es la escuela. Sin embargo, una de las conclusiones que podemos establecer preliminarmente tomando en cuenta lo dicho consiste en plantear que las lógicas exclusora y segregadora han tenido como telón de fondo la preocupación y la presencia de la escuela en tanto institución, pero que en estricto rigor no ha significado una interpelación directa a ella. Que los miembros de ciertos colectivos minoritarios hayan sido sistemáticamente excluidos de los procesos de escolarización en un caso, o agrupados en determinados contextos "apropiados" en el otro, ha conllevado a una actitud de desentendimiento por parte de la escuela ordinaria de dicha diversidad 
del alumnado. Será recién en la década de los noventa, con el surgimiento, desarrollo y predominio de los planteamientos de la inclusividad (Ainscow, 1999), que la problemática de la diversidad interpele directamente a la escuela tradicional y que obligue, por tanto, a generar un posicionamiento político y pedagógico con respecto a ésta. Es esta interpelación, las formas de resolverla y sus consecuencias las que veremos en las caracterizaciones siguientes.

\subsection{LA ESCUELA ASIMILACIONISTA}

Desde una perspectiva fáctica del término (Giménez Romero, 2009, 2003), la escuela asimilacionista es la primera escuela multicultural. La diversificación en la composición sociocultural del alumnado de estas escuelas, ante el fracaso y término de la educación segregada, puede ser caracterizada a partir de dos grandes momentos, que sin embargo comparten los principios que inspiran la lógica asimilacionista. El primero de ellos consiste en presentar una actitud básica y una voluntad de integración hacia la diversidad del alumnado, en el sentido de que se asume la importancia y la necesidad de que todo el alumnado -independiente de su condición social, étnica, económica o religiosa- tenga el derecho y la oportunidad de participar de los procesos de escolarización, y de esta manera desarrollar las competencias básicas que se requieren para la participación en el espacio social y el desarrollo armónico y exitoso de los proyectos de vida.

Por lo tanto, la escuela asimilacionista no es por principio y definición -afirmación que luego problematizaremos- una institución excluyente o exclusora con relación a determinados colectivos y a determinado alumnado. Refrescando los planteamientos de Berry (1997, 1984) y Hannoun (1992) los miembros de colectivos inmigrantes y/o minoritarios sí tienen la posibilidad de participar en y acceder a la cultura dominante y sus instituciones, siendo la escuela un ejemplo de ellas. Una segunda característica de la escuela asimilacionista, que se expresa también en sus dos grandes momentos, radica en la visión universalista (Geertz, 1996) que existe con relación a la cultura hegemónica que está a su base, y el consecuente etnocentrismo que se impregna en su praxis educativa (Liégeois, 2004; Santos Guerra, 2009). La relación entre el universalimo de la cultura propia y el etnocentrismo concomitante, tienen el riesgo, desde nuestro punto de vista, de jerarquizar las diferentes culturas, al extremo de establecer entre ellas relaciones de inferioridad/superioridad.

Es justamente a partir de lo anterior que la escuela asimilacionista presenta una voluntad integradora de la diversidad, pero bajo la creencia en la superioridad de la cultura hegemónica y la inferioridad de las culturas minoritarias y/o inmigrantes. Encontramos pues en la escuela asimilacionista una concepción academicista -cuantitativa y acumulablede la cultura (Besalú, 2002).

Es por ello que en un primer momento la escuela asimilacionista opera bajo la lógica de lo que Essomba (2006) denomina el modelo de la homogeneidad centrada en el currículo, situación en la cual las diferencias tanto culturales como individuales no gozan de importancia, por lo que la oferta educativa se basa y construye a partir de los mismos objetivos, los mismos contenidos y las mismas metodologías, todas ellas inspiradas en la cultura nacional hegemónica y teniendo como referente un alumno medio -de determinada clase social, con determinados ingresos familiares y con un determinado tipo de vivienda- (Caballero, 2001). En palabras de Santos Guerra, "La escuela tiene una inquietante función homogeneizadora. Currículum para todos, espacios para todos, evaluaciones para todos. Da la impresión de que se pretende alcanzar un individuo estandarizado que responda a los mismos patrones de 
conducta, que tenga los mismos conocimientos y que practique la misma forma de pensar" (2009: 191).

Vistas las cosas desde esta perspectiva, observamos que la escuela asimilacionista responde en primera instancia como si la presencia de un nuevo alumnado y la diversificación de éste no implicara, desde el punto de vista educativo, ninguna modificación, adaptación y, por tanto, ninguna necesidad de flexibilidad pedagógica. Esta excesiva confianza en la homogeneidad como forma de integración (Hannoun, 1992) para alcanzar las mismas oportunidades educativas, tiene como una de sus principales consecuencias el hecho de que supone para el alumnado minoritario y/o extranjero la dificultad o imposibilidad de mantener, conversar y expresar su cultura en el espacio público de la escuela. Ya sea por opción o por omisión, la escuela ve la diversidad cultural como un obstáculo que no sólo afecta al propio alumnado minoritario para el acceso a la oferta educativa, sino también para el alumnado autóctono que ve amenazado su nivel académico y el grado de atención educativa que recibe (Besalú, 2002: 64). Si bien son numerosos los autores que han contribuido con sus investigaciones y desarrollos a mostrar las consecuencias negativas de la lógica asimilacionista aplicada al ámbito educativo, autores a los que por lo demás hemos estado constantemente citando en nuestro trabajo, consideramos que los planteamientos de Essomba (2006) permiten sintetizar dichas propuestas y transmitir la brutalidad pedagógica que estos planteamientos entrañan, al señalar que intentar conseguir la igualdad educativa anulando las diferencias, no hace otra cosa que incrementar aún más la desigualdad entre el alumnado autóctono y el alumnado perteneciente a minorías culturales o perteneciente a colectivos inmigrantes.

Es justamente a partir de la valoración deficitaria que la escuela hace de las culturas no hegemónicas, y de los elevados índices de fracaso escolar entre el alumnado minoritario -explicados en función de la distancia cultural y la deficiente adaptación a la cultura escolarque la escuela asimilacionista da lugar a un segundo momento que, nuevamente siguiendo la propuesta de Essomba (2006), se constituye bajo el modelo de la heterogeneidad centrada en el currículo. A diferencia del modelo anterior, las diferencias culturales e individuales sí cobran relevancia, lo que da lugar a una cierta flexibilidad educativa que se expresa en la apuesta y creación de itinerarios educativos que contemplan diferencias en los objetivos, los contenidos y las metodologías a ser utilizadas. La heterogeneidad centrada en el currículum parte de la base de que es necesario diversificar la oferta educativa de manera que se puedan corregir los problemas que presentan el alumnado minoritario y/o inmigrante, razón por la cual la escuela asimilacionista inaugura la creación inédita de la educación compensatoria (Besalú, 2002).

En la medida que la escuela asimilacionista pone en funcionamiento una lógica educativa compensatoria que, como ya hemos visto, supone partir de la idea de que los miembros de colectivos minoritarios y/o inmigrantes presentan handicaps que deben ser nivelados (Franzé, 2003; Lalueza et al., 2001; Unamuno, 2003; Vázquez, 1984), reaparece reactualizado el predominio de una visión segregacionista del alumnado, ya no entre instituciones escolares, sino que ahora con relación a la estructura de agrupamiento del alumnado. Es una de las conclusiones a las que arriba Garreta en su investigación en torno a la atención a la diversidad en la escuela, al señalar: "Parece que el péndulo regresa hacia prácticas segregacionistas temporales ante las resistencias y dificultades de trabajar con un número importante de alumnado de origen inmigrado de múltiples orígenes y que llegan a los centros y aulas en diferentes momentos del curso y de su escolarización" (2011: 227).

Es así que en función del nivel de manejo de las competencias instrumentales básicas -cuyo ejemplo paradigmático es la lengua vehicular del centro-, las que para la escuela 
asimilacionista están condicionadas por variables culturales, se agrupa al alumnado siguiendo el criterio de la uniformidad y de sus bondades en el aprendizaje del alumnado minoritario y/o inmigrante.

Conviene destacar que desde la escuela asimilacionista y su profesorado como principal protagonista no existe, en principio, una actitud clara y derechamente discriminatoria o racista ante los colectivos minoritarios -pero la puede haber sin problemas-, ni un afán segregador, sino que se confía que a partir de este modo de funcionamiento se ofrecen más y mejores oportunidades al alumnado que se presenta como más desaventajado, rompiendo la desigualdad que presentan los procesos de enseñanza y aprendizaje únicos y comunes (Essomba, 2006), y señalando al mismo tiempo que la creación de grupos homogéneos permite rentabilizar de mejor manera los esfuerzos de especialización.

Sin embargo, pese a los principios pedagógicos utilizados y a las buenas intenciones de las políticas de discriminación positiva (Besalú, 2002) de la escuela asimilacionista, lo cierto es que ésta ha sido profundamente criticada por varias razones, provenientes de diferentes ámbitos de la educación. Desde una perspectiva crítica y amplia, se ha consensuado en reconocer que la escuela asimilacionista contribuye finalmente a promover la fragmentación escolar y social, en la medida en que al educar por separado, no se desarrollan las competencias necesarias para enfrentar entornos postescolares, domésticos, laborales o recreativos de la comunidad que son de naturaleza fundamentalmente heterogénea (Pujolàs, 2012). Desde el punto de vista de la socialización como finalidad educativa (Sandín, 1999), se ha documentado mucho material etnográfico que ha alertado -y hasta cierto punto denunciadode lo perjudicial que resulta el desarrollo integral del alumnado minoritario en contextos escolares en los que deben renunciar a sus culturas -tanto desde el punto de vista expresivo como profundo- e incorporar, muchas veces de manera conflictiva y disarmónica, las pautas culturales del grupo hegemónico (Jackson, 2001). Esto ha impedido, por tanto, que el alumnado minoritario y/o inmigrante pueda desarrollar de forma exitosa la biculturalidad, es decir, la capacidad de desarrollar procesos de aculturación sin renunciar necesariamente a los referentes culturales, familiares y étnicos. El excesivo peso e importancia que se le ha dado a la vertiente instruccional y procedimental de la educación (Jordán, 1999), ha provocado un desentendimiento por parte de la escuela asimilacionista con relación al éxito de todos y cada uno de los y las estudiantes. La sentencia más o menos generalizada ha sido que el fracaso escolar ha sido responsabilidad mayormente de la escuela y no del alumnado minoritario y/o extranjero (Poveda, 2003). Finalmente, y desde la especificidad de la praxis pedagógica, se ha demostrado que la configuración de grupos heterogéneos de trabajo favorece mayormente el aprendizaje, sin descuidar por cierto el valor que las interacciones juegan para los procesos de socialización (Díaz-Aguado, 2003; Jordán, 1996; Vázquez y Martínez, 1996).

\subsection{LA ESCUELA MULTICULTURALISTA}

Si bien ya lo habíamos mencionado en el apartado de los modelos en el espacio social, vale recordar que los modelos van surgiendo y consolidándose en función de los fracasos, los vacíos y las deudas de los modelos anteriores. En el ámbito de la educación ocurre lo mismo: la escuela multiculturalista surge a partir de las críticas recibidas por la escuela asimilacionista sobre su incapacidad de dar respuesta y solución a las principales problemáticas que entrañan. Mencionamos introductoriamente y en términos generales el fracaso escolar y sus modalidades asociadas -bajos resultados, absentismo, abandono- como una de las principales 
problemáticas que la llegada de alumnado inmigrante ha significado para las escuelas, lo que puede ser complementado con las críticas formuladas recientemente hacia la escuela asimilacionista en cuanto reproductora de las dificultades de desarrollo de la biculturalidad del alumnado minoritario y/o inmigrante, y perpetuadora de la desigualdad y las dificultades de integración a propósito de la lógica compensatoria (Garreta y Llevot, 2003). Si hay una razón por la cual surge la escuela multiculturalista es justamente para poner freno a estas dificultades y poder generar experiencias educativas que sean universalmente beneficiosas para todos y cada uno de los alumnos y alumnas que participan de ella, independiente de la pertenencia a determinada étnia, grupo social, status socioeconómico o profesión religiosa.

Es en función de lo anterior que la escuela multiculturalista se constituye como una forma de superación de la escuela asimilacionista, rescatando de ésta el interés y la preocupación por el alumnado minoritario y/o inmigrante que se expresa en su voluntad integracionista, pero que añade, no obstante, un elemento central y diferenciador que corresponde al énfasis puesto en el reconocimiento y el respeto hacia las diferencias. El siguiente pasaje expresa acertadamente el espíritu multiculturalista, cuando Santos Guerra plantea que:

Si el asimilacionismo homogeneiza, vamos a no homogeneizar y a valorar la cultura de los demás. Huyamos de los grupos homogéneos que disminuyen el rendimiento escolar, guetizan y disminuyen la igualdad de oportunidades. Si el asimilacionismo destina sus esfuerzos a las minorías, vamos a trabajar no sólo para la minoría, dediquemos el mismo esfuerzo a trabajar con el colectivo de cultura mayoritaria que es igual o más responsable de que se produzcan verdaderos encuentros (2009: 74).

Tales planteamientos suponen, por tanto, un rechazo a la lógica segregacionista de segundo orden ${ }^{4}$ presente hasta entonces y amparada en la idea del déficit y la compensación, poniendo en su lugar la preocupación e importancia del reconocimiento de las diferencias en el ámbito escolar, y de la relevancia y pertinencia en desarrollar experiencias educativas de contacto multicultural.

Si bajo un predominio compensatorio el alumnado era mayoritariamente agrupado y separado bajo ciertos criterios -origen y rendimiento fundamentalmente- con el objeto de facilitar la adaptación a la cultura escolar y el logro de los objetivos pedagógicos, las posibilidades de interacción e intercambio entre el alumnado mayoritario y el minoritario se veían drásticamente reducidas, restringiéndose las oportunidades de conocimiento y respeto hacia las diferencias culturales. Esta preocupación por los intercambios culturales por parte de la escuela multiculturalista inaugura una nueva forma de gestionar la diversidad cultural en la cual el centro de interés ya no será exclusivamente lo pedagógico, entendido como ciertos objetivos que se traducen en determinados contenidos que se abordan a partir de una metodología puntual, sino que se interesará en el desarrollo en el amplio sentido del término y, por ende, en toda su dimensión (Essomba, 2006).

Dos consecuencias de esta nueva forma de entender los procesos de escolarización contemplando la diversidad sociocultural del alumnado las encontramos en el retorno hacia un currículum centralizado, pero adaptado, y en la normalización de los procesos de

Llamamos segregacionismo de segundo orden a aquel que tiene lugar al interior de las escuelas asimilacionistas como resultado de la aplicación de una lógica de especialización y el consecuente agrupamiento homogéneo del alumnado. El segregacionismo de primer orden correspondería a aquel que tiene lugar en la creación de escuelas homogéneas y especializadas para satisfacer las necesidades de un particular tipo de alumnado. 
enseñanza y aprendizaje. La primera de ellas consiste en que en la escuela multiculturalista dejan de existir dos currículum e itinerarios educativos (para autóctonos e inmigrantes/ minoritarios), dando lugar a uno único, el cual, no obstante, tiene la virtud de introducir modificaciones de manera que permita incorporar a las culturas de los diferentes grupos culturales representados por el alumnado. La aditividad étnica en el currículum (Banks, 1989) permite que éste contemple los saberes personales y culturales de la diversidad del alumnado (Banks, 1995), otorgando, así, una mirada más relativa y completa de las temáticas y contenidos abordados en los procesos de enseñanza y aprendizaje, así como la oportunidad de que el alumnado minoritario y/o extranjero pueda tomar como referencia en dichos procesos sus referentes culturales. La superación del enfoque eurocéntrico para abordar la historia, la revisión de la geografía física y humana de las zonas de origen del alumnado minoritario y/o inmigrante, una mirada más universal de la literatura, así como cursos de religión comparada (Besalú, 2002), son ejemplos de la multiculturalización del currículum escolar. Detrás de esta innovación en el diseño y la praxis educativa está el convencimiento de que se crean mayores oportunidades educativas para el alumnado minoritario y/o extranjero, lo que finalmente permite igualarlas con relación a las del alumnado autóctono. La segunda consecuencia radica en el hecho de que en tanto dejan de existir itinerarios y espacios diferenciados para el alumnado, durante los procesos de enseñanza y aprendizaje se proporciona al alumnado minoritario y/o extranjero las condiciones lo más parecidas posible a las del resto de la mayoría social (Essomba, 2006).

Sin embargo, como ya hemos advertido anteriormente, la escuela multiculturalista no se agota en la vertiente pedagógica y en el tipo o calidad de los contenidos incluidos dentro de la oferta educativa. Para la escuela multiculturalista resulta central dentro del desarrollo la socialización del alumnado, y es por ello que la pondrá en un lugar prioritario de sus prácticas. Como señala Ogbu (1988), el desarrollo de identidades positivas por parte del alumnado se constituye en uno de los objetivos centrales de la educación actual y del logro de oportunidades igualitarias. No obstante, al mismo tiempo, el desarrollo de la identidad es un proceso que se da necesariamente en interacciones con los otros (Taylor, 1996), y que no puede darse en la privacidad de la experiencia solitaria. Es en esta línea que la escuela multiculturalista privilegia las estrategias de contacto utilizando metodologías que acerquen al alumnado perteneciente a diferentes colectivos, estimulando el conocimiento mutuo y la promoción del diálogo (Díez Gutiérrez, 2004), de modo de otorgarle un carácter positivo a las diferencias culturales. Ahora bien, es importante tomar en consideración que la aceptación del pluralismo cultural en la escuela, entendida como la integración del alumnado inmigrante y/o minoritario, así como el respeto a las diferencias, entendidos como los ejes fundamentales sobre los que pensar y diseñar la atención a la diversidad, no son suficientes a la hora de abordar y resolver los problemas que el multiculturalismo produce y visibiliza en la escuela. El hecho de relativizar el centro de gravedad de los contenidos curriculares, y el hecho de promover experiencias de descubrimiento y contacto cultural, resultan iniciativas insuficientes para garantizar la igualdad de oportunidades en el ámbito educativo. Como plantea Liégeois (2004), el predominio de una pedagogía de bricolaje superficial, para referirse al multiculturalismo, mantiene muchas veces intactas las actitudes de rechazo y las relaciones de desigualdad entre el alumnado inmigrante y/o minoritario y los miembros pertenecientes a la cultura dominante, ya sea por parte del alumnado o bien del profesorado.

El concepto de folklorismo pedagógico acuñado por Hannoun (1992) sintetiza la idea/ advertencia -contrastada y documentada en diversas investigaciones citadas en nuestro 
trabajo- de la peligrosidad e inutilidad de los planteamientos multiculturales cuando éstos son llevados a la práctica de manera superficial, liviana y acrítica, en la medida que no permiten satisfacer los objetivos que justamente se persiguen, contribuyendo incluso a reforzar estereotipos y conceptos errados con relación a la diversidad cultural (Banks, 1989). Tomando como referencia los estadios de desarrollo propuestos por Michael (1997) en torno a la aproximación organizacional a la diversidad cultural, podríamos decir que si bien la escuela multiculturalista logra superar el estadio del pluralismo cultural, centrado en una valoración positiva de la diversidad, se posiciona, no obstante, de manera débil e inestable en el estadio de gestión de la diversidad. Esto quiere decir que pese a los cambios introducidos en la práctica educativa en la línea de respetar las diferencias y de enfocar la enseñanza desde distintas perspectivas (Essomba, 2008), no logra impregnar las prácticas educativas con el convencimiento de que la heterogeneidad y diversidad del alumnado es materia prima para el enriquecimiento mutuo, permaneciendo, entonces, de manera solapada una forma jerarquizada de entender la relación entre las culturas de origen del alumnado.

\subsection{LA ESCUELA INTERCULTURALISTA}

Es conveniente comenzar una exposición en torno a la perspectiva intercultural en la escuela explicitando el convencimiento de que, a diferencia de las modalidades de escuela antes descritas, si bien existen en la actualidad experiencias concretas y reconocibles que giran en torno a los planteamientos propuestos por la escuela interculturalista, en última instancia ésta continúa siendo más un proyecto que una realidad constatada (Essomba, 1999). Como lo han demostrado Garreta y Llevot (2003) para el contexto europeo a través del ejemplo catalán, así como Luna e Hirmas (2004) para el caso latinoamericano con el ejemplo chileno $^{5}$, si bien los planteamientos sobre la interculturalidad han hecho eco en el ámbito de la educación, y han logrado infiltrar, por tanto, las políticas públicas en tanto directrices, lo cierto es que aun cuando los discursos predominantes de la escuela -a través de sus actores principales- presentan muchas veces alusiones hacia componentes y preocupaciones de orden intercultural, las prácticas pedagógicas continúan desarrollándose fundamentalmente bajo lógicas asimilacionistas y, en el mejor de los escenarios, multiculturalistas. Es de esta manera que asumir la calidad de "proyecto" del paradigma intercultural en la escuela, permite reconocer además en éste el carácter de actitud y deseo (Caballero, 2001): no sólo es algo que está en construcción, sino que además es algo que se anhela, en tanto representa la manera ideológico-política más coherente y significativa para lograr calidad e igualdad educativa para todo el alumnado, sin perder de vista la diversidad cultural.

Una vez realizada esta aclaración es el momento de revisar los planteamientos de la escuela intercultural y sus críticas hacia lo realizado por la escuela multiculturalista. Un primer elemento a destacar dentro de los planteamientos de la escuela interculturalista ha sido el denunciar la equivocación existente en establecer una relación unívoca entre interculturalidad y minorías. Esta asociación ha tenido como consecuencia que la escuela

Si bien tomamos en consideración ambos ejemplos de manera general, es importante no perder de vista que los orígenes del movimiento intercultural en la escuela obedecen a contextos socio-históricos muy diferentes que condicionan sus planteamientos políticos, sus alcances y sus objetivos. Así como el interculturalismo surge en Europa a partir de los movimientos migratorios, en Latinoamérica lo hace más bien por la presión reivindicativa de los pueblos indígenas hacia el Estado. Esto implica que, desde el plano específicamente educativo, la educación intercultural europea privilegie el espacio de la convivencia, mientras que la educación intercultural latinoamericana privilegie el espacio curricular. 
multiculturalista haya sido pensada exclusivamente para aquellos contextos escolares que contaban con una alta participación de alumnado inmigrante y/o minoritario. Ha sido un primer planteamiento de la escuela interculturalista el señalar que la educación intercultural no debe ser destinada sólo para contextos heterogéneos y multiculturales, sino que debe ser algo universal (Abdallah-Pretceille, 2001), incluso más, cuya utilidad y beneficios serían más provechosos para aquellos centros en los que no existe alumnado minoritario y/o extranjero, puesto que es ese alumnado el que en principio es más incompetente e ignorante desde el punto de vista intercultural, y el que menos posibilidades presenta de modificar o ampliar su punto de vista etnocéntrico (Besalú, 1999).

Un segundo elemento a recalcar de la escuela interculturalista consiste justamente en que, a diferencia de la importancia dada por la escuela multiculturalista a la acción socioeducativa centrada en las diferencias culturales, ésta centra su accionar socioeducativo desde el reconocimiento, no aceptación y transformación de las desigualdades culturales en el contexto escolar (Essomba, 2006). Es a partir de este propósito que la escuela interculturalista propone de entrada dos cambios: reconsiderar la importancia de la igualdad entendida como los aspectos comunes a través de la diversidad cultural, y superar el etnocentrismo de la escuela multicultural.

Por un lado, reconsiderar la importancia de la igualdad no es otra cosa que reconocer que el énfasis en elogiar las diferencias tiene como resultado final el distanciamiento entre el alumnado perteneciente a diferentes culturas o etnias. El trabajo en torno al reconocimiento de las diferencias, si bien supone un logro inicial en tanto permite al alumnado conocer y reconocer elementos que anteriormente eran ignorados, tiene como contraparte el contribuir implícitamente a acrecentar la distancia entre el alumnado perteneciente a diferentes culturas y/o etnias.

Por otro lado, superar el etnocentrismo escolar supone la capacidad de la escuela, como señala Banks (1989), en diseñar e implementar una oferta educativa que tenga la capacidad de ir más allá de los criterios y perspectivas del pensamiento hegemónico eurocéntrico, ofreciendo al alumnado la posibilidad de ver la realidad social y los contenidos curriculares desde diferentes perspectivas culturales y étnicas. Si la escuela multicultural ha entendido la igualdad educativa sólo como la incorporación de referentes culturales minoritarios al espacio escolar, la escuela intercultural ha entendido la igualdad educativa como la incorporación de referentes culturales al espacio escolar de manera que tanto la perspectiva hegemónica como las perspectivas minoritarias contribuyan a la comprensión de la realidad, avanzando desde el saber académico corriente al saber académico transformador (Banks, 1995). Yace en esta manera de conceptualizar la igualdad la convicción de que la educación en contextos multiculturales no consiste en la adaptación de los grupos minoritarios a la cultura hegemónica, sino que es el alumnado en su conjunto y totalidad quien debe, con la ayuda del profesorado, construir un nuevo marco cultural fundamentado en la interculturalidad.

Otro elemento que permite diferenciar a la escuela intercultural de su antecesora multicultural radica en la importancia dada por la primera a las continuidades entre diferentes contextos ecológicos (Bronfenbrenner, 1987), de manera de no centralizar el desarrollo de la interculturalidad en el contexto escolar, asumiendo que el logro de ella depende del trabajo articulado de más entornos educativos. Para la escuela intercultural resulta central, por tanto, el establecimiento de continuidades con el ámbito familiar y con los contextos comunitarios y sociales inmediatos del alumnado, de modo de evitar el asincronismo 
(McCarthy, 1994) entre los diferentes contextos y sus posibles contradicciones. En la medida que la escuela intercultural entiende la educación como una actividad cultural que no se agota en el espacio escolar (Serra, 2004), el resto de espacios de socialización cobran relevancia para el logro de los objetivos interculturales.

Finalmente, y ahondando un poco más la mirada hacia los procesos educativos propiamente tales, observamos que a diferencia de la escuela multiculturalista y su énfasis en la integración como modelo de gestión de la diversidad cultural, la escuela intercultural apuesta por desarrollar una perspectiva con una clara orientación y vocación inclusiva. Dicho de otra manera, si bien la escuela intercultural no puede ser entendida como sinónimo de educación inclusiva, conviene concebir ambas perspectivas de una manera intrínsecamente articulada que, compartiendo y operando bajo los mismos principios reseñados anteriormente, obedecen a planos distintos (Essomba, 2006). Desde nuestro punto de vista, entonces, la educación inclusiva corresponde al correlato pedagógico de la educación y de la escuela intercultural. La educación inclusiva como correlato pedagógico en la escuela intercultural no persigue otro objetivo que lograr el éxito y la calidad educativa de todo el alumnado (Sandoval et al., 2002), que desde un punto de vista multicultural lo supone tanto para el alumnado mayoritario como minoritario. Es, por ende, una forma de entender la educación que aboga por eliminar los sistemas duales característicos de la escuela segregacionista de segundo orden, así como evitar la exclusión de los modelos previos a ésta. Echeita sintetiza muy bien el objetivo de la educación inclusiva al señalar:

\begin{abstract}
¿Por qué hablamos de educación inclusiva? La respuesta más sencilla y directa sería que lo hacemos para «frenar» y cambiar la orientación de unas sociedades en que los procesos de «exclusión social» son cada vez más fuertes y, por esta razón, empujan a un número cada vez mayor de ciudadanos (y a países enteros) a vivir su vida por debajo de los niveles de dignidad e igualdad a los que todos tenemos derecho (2002: 31 ).
\end{abstract}

La respuesta dada por el autor nos permite hacer al menos dos reflexiones. La primera guarda relación con lo dicho anteriormente en la medida que la educación inclusiva como paradigma de la escuela intercultural establece una estrecha conexión entre el sistema educativo y el contexto social mayor. La segunda se refiere a que para la escuela intercultural la inclusividad es la estrategia idónea para garantizar la igualdad de oportunidades y de éxito escolar para todo el alumnado, independiente del origen y de la pertenencia a determinados colectivos mayoritarios y/o minoritarios. En cierta medida, la predominancia de formas asimilacionistas y multiculturalistas de pensar y configurar la escuela, no hace otra cosa que condenar al alumnado minoritario al fracaso escolar y, por tanto, a la exclusión social. Son justamente estas consecuencias las que la escuela intercultural, a través de su perspectiva inclusiva, intenta frenar y modificar. Como propone Essomba:

Para diseñar aulas y escuelas auténticamente inclusivas, hace falta partir del principio de que todos los alumnos de una clase pertenecen al grupo, y que todos pueden aprender en la vida normal de la escuela y del barrio o pueblo. Para conseguirlo, el modelo de inclusión no se mueve entre la dicotomía de «contenidos generales-contenidos específicos», sino que comprende que deben existir unos contenidos comunes a todo el alumnado, y después unos contenidos específicos que respondan a las características propias de cada individuo (2006: 92). 
De esta manera, se zanja la discusión en torno a la pertinencia de operar en contextos de diversidad bajo la lógica de la especialización (que para la escuela segregacionista consiste en ofrecer itinerarios educativos diferentes), o bien bajo la lógica de la incorporación (que para la escuela asimilacionista implica un itinerario único con estrategias de compensación), realizando un salto dialéctico que permite ofrecer una experiencia educativa flexible y significativa que implique no una adaptación del alumnado, sino del currículum, sus contenidos y actividades educativas. Si bien ya hemos advertido anteriormente que la educación intercultural -a lo que añadimos ahora la educación inclusiva- no debiera corresponder únicamente a contextos sociales y escolares con presencia de alumnado minoritario y/o inmigrante, para los efectos de nuestro trabajo resulta pertinente observar cómo opera la lógica de la inclusividad en este tipo de escuelas.

La inclusión educativa de la escuela intercultural se materializa en que, desde el punto de vista psicopedagógico, los procesos de enseñanza y aprendizaje son pensados y llevados a cabo desde una óptica equitativa (Abdallah-Pretceille, 2001), articulación que se plasma en la adaptación de los programas de enseñanza de manera de facilitar el éxito académico y la inserción social de todo el alumnado, independiente del origen cultural de éste. El éxito académico y la inserción social al grupo curso de todo el alumnado -incluyendo el minoritario y/o extranjero- se logra en la medida que se reconocen y eliminan las barreras para el aprendizaje y la participación que puedan presentarse para el alumnado (Ainscow, 1999). La educación inclusiva que la escuela intercultural promueve deja de hablar de necesidades educativas especiales, en tanto que las dificultades que manifiesta muchas veces parte del alumnado no son explicadas en términos de realidades sustantivas de éste, sino más bien como configuraciones interaccionales entre los y las estudiantes y sus contextos -compañeros y profesorado principalmente- que inhiben o dificultan las posibilidades de éxito de dicho alumnado (Barton, 1998).

En consecuencia, para la escuela intercultural la inclusión se logra en la medida que sus actores -principalmente el profesorado- desarrollan sus procesos de enseñanza y aprendizaje de manera que minimicen las barreras y maximicen los recursos destinados al alumnado que mayores ayudas requiere para el éxito educativo y la participación activa de dichos procesos educativos. La inclusión educativa de la escuela intercultural permite reunir en un mismo contexto educativo y en un mismo sistema de actividad a alumnado perteneciente a culturas mayoritarias y minoritarias y/o extranjeras, sin que exista la necesidad de que el alumnado sea separado por niveles o incluso por establecimientos como en la escuela segregacionista, o atendidos bajo una lógica compensatoria como ocurre en la escuela asimilacionista. Desde nuestro punto de vista, sólo la escuela intercultural, a través de su apuesta por la inclusión educativa de todo el alumnado, logra resolver adecuada y armónicamente la tensión que presentan los contextos educativos multiculturales, fácticamente hablando, entre el desarrollo de la comprensividad y la atención a la diversidad, evitando la desigualdad y la exclusión (Echeita, 2002).

\section{DESAFIOS PARA NUESTRO CONTEXTO LOCAL}

Como señalamos al inicio de nuestro trabajo, si bien existen en nuestro país investigaciones en el campo de la educación intercultural y que, por tanto, contemplan la pregunta por los modelos de gestión de la diversidad cultural, dichas investigaciones han estado orientadas y centradas en los procesos de escolarización de alumnado perteneciente a 
las minorías étnicas reconocidas en la ley indígena. Esto ha tenido como consecuencia que no contemos en la actualidad con suficiente información para saber qué modelos predominan en las escuelas que cuentan con presencia de alumnado inmigrante.

Si bien el conocimiento de los modelos de gestión predominantes en las escuelas se constituye en un primer desafío, resulta necesario conocer qué modelos existen desde el punto de vista de la teoría, y que son los que han sido utilizados para investigaciones en países con mayor tradición en educación en contextos multiculturales. Sin embargo, el conocimiento teórico de diferentes modelos de gestión de la diversidad cultural no se agota en el aporte que éstos puedan dar a la investigación educativa, sino que pueden -y deben- servir también como "lentes" para los propios equipos directivos y equipos de profesores cuyas escuelas escolaricen alumnado inmigrante, para contar con información relevante para poder mirar, examinar y reflexionar en torno a sus propias realidades, sus propias prácticas y principios, y valorar, en consecuencia, cuál es el modelo predominante en materia de gestión de la diversidad cultural.

Finalmente, un tercer desafío para nuestra realidad local -y sin duda el principalradica en la necesidad de promover en los contextos educativos multiculturales un interés, una voluntad y una necesidad al fin y al cabo por desplegar modelos de gestión inspirados en los principios de la interculturalidad y la educación inclusiva, de manera que nuestras próximas investigaciones no nos corroboren que hemos seguido el mismo camino que otros países y que la escolarización del alumnado inmigrante presente mayores niveles de fracaso que las de los estudiantes autóctonos. Debemos pensar la interculturalidad, en primera instancia, como un freno al fracaso escolar y como freno, por tanto, al desarrollo de una educación basada en la desigualdad de oportunidades y en la no valoración de la diversidad cultural.

\section{REFERENCIAS BIBLIOGRÁFICAS}

Abdallah-Pretceille, M. (2001). La educación intercultural. Barcelona: IDEA Books.

Ainscow, M. (1999). Desarrollo de escuelas inclusivas. Madrid: Narcea.

Banks, J. A. (1995). El debate canónico, la construcción del conocimiento y la educación multicultural. Revista Kikiriki, n. 41, 4-16.

(1989). Approaches to Multicultural Curriculum Reform. Trotter Review, vol. 3, n. 3. Recuperado de http://scholarworks.umb.edu/trotter_review/vol3/iss3/5, consultado en marzo de 2013. (1986). Multicultural Education: Development, Paradigms and Goals. En J. A. Banks \&

J. Lynch (Eds.), Multicultural Education in Western Societies (pp. 12-28). London: Holt, Rinehart and Winston.

Barton, L. (1998). Sociología y discapacidad: Algunos temas nuevos. En L. Barton (Comp.), Discapacidad y sociedad (pp. 21-33). Madrid: Morata.

Berry, J. W. (1997). Inmigration, Acculturation and Adaptation. Applied Psychology: An International Review, vol. 46, n. 1, 5-68.

(1984). Cultural Relations in Plural Societies: Alternatives to Segregation and their Sociopsychological Implications. En B. Miller \& M. Brewer (Eds.), Groups in Contact: The Psychology of Desegregation (pp. 11-27). London: Academic Press.

Besalú, X. y Vila, I. (2007). La buena educación: Libertad e igualdad en la escuela del siglo $X X I$. Madrid: Los Libros de la Catarata. . (2002). Diversidad cultural y educación. Madrid: Síntesis.

Besalú, X. (1999). El currículum. En M. A. Essomba (Coord.), Construir la escuela intercultural: 
Estudios Pedagógicos XL, $\mathrm{N}^{\circ}$ 2: 409-426, 2014

MODELOS DE GESTIÓN DE LA DIVERSIDAD CULTURAL PARA LA ESCOLARIZACIÓN DE ALUMNADO

INMIGRANTE EN LAS ESCUELAS CHILENAS: DESAFÍOS PARA LA INTERCULTURALIDAD ACTUAL

Reflexiones y propuestas para trabajar la diversidad étnica y cultural (pp. 91-101). Barcelona: Graó.

Bourdieu, P. (2005). Capital cultural, escuela y espacio social. Ciudad de México: Siglo XXI.

y Passeron, J. C. (1995). La reproducción. Elementos para una teoría del sistema de

enseñanza. Ciudad de México: Distribuciones Fontamara.

Bronfenbrenner, U. (1987). La ecología del desarrollo humano. Barcelona: Paidós.

Caballero, Z. (2001). Aulas de colores y sueños: La cotidianeidad en las escuelas multiculturales. Barcelona: Octaedro.

Canimas, J. y Carbonell, F. (2008). Educació i conflictes interculturals. Primun Non Nocere. Barcelona: Fundació Jaume Bofill.

COLECTIVO AMANI. (2004). La escuela intercultural: Regulación de conflictos en contextos multiculturales. Madrid: Los libros de la Catarata.

Díaz-Aguado, M. J. (2003). Educación intercultural y aprendizaje cooperativo. Madrid: Pirámide.

Díez Gutiérrez, E. J. (2004). Interculturalidad, convivencia y conflicto. Revista Tabanque, n. 18, 49-76

Echeita, G. (2002). Educación inclusiva o educación sin exclusiones. Revista de Educación, n. 327, 31-48.

Essomba, M. A. (2008). 10 ideas clave: La gestión de la diversidad cultural en la escuela. Barcelona: Graó.

(2006). Liderar escuelas interculturales e inclusivas. Equipos directivos y profesorado ante la diversidad cultural y la inmigración. Barcelona: Graó.

(1999). Construir la escuela intercultural. Reflexiones y propuestas para trabajar la diversidad étnica y cultural. Barcelona: Graó.

Franzé, A. (2003). Las formas escolares del extrañamiento: Un estudio de los intercambios comunicativos en un contexto intercultural. En D. Poveda (Coord.), Entre la diferencia y el conflicto. Miradas etnográficas a la diversidad cultural en educación (pp. 99-138). Cuenca: Ediciones de la Universidad de Castilla-La Mancha.

García-Gómez, L. y Aldana-González, G. (2010). Cultura escolar: Un elemento indispensable para comprender los procesos de inclusión educativa. Revista Acción Pedagógica, vol. 19, n. 1, 116-125.

Garreta, J. (2011). La atención a la diversidad cultural en Cataluña: Exclusión, segregación e interculturalidad. Revista de Educación, n. 355, 213-233.

y Llevot, N. (2003). El espejismo intercultural. La escuela de Cataluña ante la diversidad cultural. Madrid: CIDE.

Geertz, C. (1996). Los usos de la diversidad. Barcelona: Paidós.

Giménez Romero, C. (2009). Interculturalisme. Definició, especificitat i dimensions. Barcelona Societat. Revista de Coneixement i Anàlisi Social, n. 16, 32-41.

(2003). Pluralismo, multiculturalismo e interculturalidad. Propuestas de clarificación y apuntes educativos. Revista de Investigación Aplicada y Experiencias Educativas, n. 8, 9-26.

Hannoun, H. (1992). Els guettos de l'escola. Per una educació intercultural. Vic: EUMO Editorial.

Instituto Nacional de Estadísticas (INE). (2012). Resultados Preliminares Censo de Población

$y$ Vivienda 2012. Santiago de Chile. Recuperado de http://www.censo.cl/2012/08/resultados_ preliminares_censo_2012.pdf, consultado en marzo de 2013.

Jackson, P. (2001). La vida en las aulas. Madrid: Morata.

Jiménez, F. (2012). Violencia escolar en contextos educativos multiculturales: Una aproximación desde los modelos de gestión de la diversidad cultural. Psicoperspectivas, vol. 11, n. 2, 8-30.

Jordán, J. A. (1999). El profesorado ante la educación intercultural. En M. A. Essomba (Coord.), Construir la escuela intercultural. Reflexiones y propuestas para trabajar la diversidad étnica y cultural (pp. 65-74). Barcelona: Graó.

(1996). La escuela multicultural: Un reto para el profesorado. Barcelona: Paidós.

Lalueza, J. L., Crespo, I. y Luque, M. J. (2010). Un espai de col-laboració entre la Comunitat 
Gitana i la Universitat per a l'educació intercultural. Revista Perspectiva Escolar, n. 349, 46-55.

. (2009). El projecte Shere Rom: Espais educatius d'us de les noves tecnologies per al desevolupament comunitari. Barcelona Societat. Revista de Coneixement i Anàlisi Social, n. 16, 129136.

., Crespo, I., Pallí, C. y Luque, M. J. (2001). Socialización y cambio cultural en una comunidad étnica minoritaria. El nicho evolutivo gitano. Cultura y Educación, vol. 13, n. 1, 115-130.

Liégeois, J. P. (2004). La escolarización de los niños gitanos: Un reto y un paradigma para la educación intercultural. Revista Educatio Siglo XXI, n. 22, 91-123.

Luna, L. e Hirmas, C. (2004). Enfoques curriculares de educación intercultural en Chile: Análisis para una propuesta de convivencia. Ponencia presentada en el VI Congreso Latinoamericano de Educación Intercultural Bilingüe (pp. 1-18). Santiago, Chile.

McCarthy, C. (1994). Racismo y currículum. La desigualdad social y las teorías políticas de las diferencias en la investigación contemporánea sobre la enseñanza. Madrid: Morata.

Michael, S. O. (1997). Models of Multiculturalism: Implications fot the Twenty-five Century Leaders. European Journal of Intercultural Studies, vol. 8, n. 3, 231-245.

MINEDUC. (2002). Aspectos generales de la Educación Intercultural Bilingüe (EIB) y sus fundamentos. Santiago de Chile. Recuperado de http://www.mineduc.cl/index2.php?id_ portal=28\&id_seccion=3413\&id_contenido=13936, consultado en marzo de 2013.

Montecinos, C. (2004). Analizando la política de educación intercultural bilingüe en Chile desde la educación multicultural. Cuadernos Interculturales, vol. 2, n. 3, 35-44.

Ogbu, J. (2005). Etnografía escolar. Una aproximación a nivel múltiple. En Á. Díaz de Rada, H. Velasco y F. García (Eds.), Lecturas de antropología para educadores. El ámbito de la antropología de la educación y de la etnografía escolar (pp. 145-174). Madrid: Trotta.

(1988). Class Stratification, Racial Stratification, and Schooling. En L. Weiss (Ed.),

Clase, Race \& Gender in American Education (pp. 63-82). Nueva York: State University of New York Press.

Perrenoud, P. (1998). ¿A dónde van las pedagogías diferenciadas? Hacia la individualización del currículo y de los itinerarios formativos. Revista Educar, n. 22-23, 11-34.

Poveda, D. (2003). Saberes sociolinguísticos en una clase multicultural. En D. Poveda (Coord.), Entre la diferencia y el conflicto. Miradas etnográficas a la diversidad cultural en educación (pp. 67-98). Cuenca: Ediciones de la Universidad de Castilla-La Mancha.

Pujolàs, P. (2012). Aulas inclusivas y aprendizaje cooperativo. Educatio Siglo XXI, vol. 30, n. 1, 89-112.

San Román, T. (1998). Escuela y relaciones interétnicas. En E. Santamaría y F. González (Coords.), Contra el fundamentalismo escolar. Reflexiones sobre educación, escolarización y diversidad cultural (pp. 73-90). Bilbao: Virus.

Sandín, M. P. (1999). La socialización del alumnado en contextos multiculturales. En M. A. Essomba (Coord.), Construir la escuela intercultural: Reflexiones y propuestas para trabajar la diversidad étnica y cultural (pp. 37-46). Barcelona: Graó.

Sandoval, M., Lopez, M. L., Miquel, E., Durán, D., Giné, C. y Echeita, G. (2002). Index for Inclusion. Una guía para la evaluación y mejora de la educación inclusiva. Revista Contextos Educativos, n. 5, 227-238.

Santos Guerra, M. Á. (2009). El valor de la convivencia y el reto de la interculturalidad. Eikasia, Revista de Filosofía, vol. 5, n. 28, 175-200.

Serra, C. (2004). Etnografía escolar, etnografía de la educación. Revista de Educación, n. 334 , 165-176.

Subirats, M. (1994). Conquistar la igualdad: Coeducación hoy. Revista Iberoamericana de Educación, n. 6, 49-78.

Taylor, C. (1996). Identidad y reconocimiento. Revista Internacional de Filosofía Política, n. 7 , 10-19. 
Estudios Pedagógicos XL, N²: 409-426, 2014

MODELOS DE GESTIÓN DE LA DIVERSIDAD CULTURAL PARA LA ESCOLARIZACIÓN DE ALUMNADO

INMIGRANTE EN LAS ESCUELAS CHILENAS: DESAFÍOS PARA LA INTERCULTURALIDAD ACTUAL

Torres Santomé, J. (2008). Diversidad cultural y contenidos curriculares. Revista de Educación, n. $345,83-110$.

Unamuno, V. (2003). Quién es qui a l'escola?: El reto de observarnos diversos. En D. Poveda (Coord.), Entre la diferencia y el conflicto. Miradas etnográficas a la diversidad cultural en educación (pp. 31-66). Cuenca: Ediciones de la Universidad de Castilla-La Mancha.

UNESCO. (2009). Educación y diversidad cultural: Lecciones desde la práctica innovadora en América Latina. Santiago: OREALC/UNESCO.

Vázquez, A. (1984). Rápido y bien: Los conflictos de los niños extranjeros en la escuela francesa. Revista Infancia y Aprendizaje, vol. 7, n. 26, 95-110.

Vázquez, A. y Martínez, I. (1996). La socialización en la escuela. Una perspectiva etnográfica. Barcelona: Paidós. 